Research Article

\title{
Genotoxic evaluation of ornidazole and secnidazole in albino mice: an experimental study
}

\author{
Shreenivas P. Revankar*, Vedavathi H
}

Department of Pharmacology and Pharmacotherapeutics, Shimoga Institute of Medical Sciences, Shimoga-577201, Karnataka, India

Received: 30 November 2013 Accepted: 15 December 2013

\section{*Correspondence to:}

Dr. Shreenivas P. Revankar, Email: sprevankar@yahoo.com

(C) 2014 Revankar SP et al. This is an open-access article distributed under the terms of the Creative Commons Attribution Non-Commercial License, which permits unrestricted non-commercial use, distribution, and reproduction in any medium, provided the original work is properly cited.

\begin{abstract}
Background: The present study was planned to explore the genotoxic potential of some commonly used antimicrobials like ornidazole and secnidazole in swiss albino mice.

Methods: Therapeutic equivalent doses of ornidazole and secnidazole were given by intra peritoneal route. Single dose in individual groups of mice $(n=5$ in each) was administered for acute study. Doses were repeated every $24 \mathrm{hrs}$ for 7 times in additional groups of mice ( $\mathrm{n}=5$ in each) for sub-acute study. Cyclophosphamide served as positive control while normal saline as negative control. After $24 \mathrm{hrs}$ of single dose (acute study) and last dose of drug administration in sub-acute study, about $0.5 \mathrm{ml}$ of blood was collected by retro orbital sinus for comet assay as described earlier (Rojas E et al, 1999) and later the mice were sacrificed to aspirate the femoral bone marrow for micronucleus test as described earlier by described by Schmid W (1975). In comet assay, the total comet length and head diameter was measured under microscope using ocular \& stage micrometer to calculate comet tail length. In micronucleus assay, the stained bone marrow tissue smears were scored for the frequency of micronucleated polychromatic erythrocytes (MnPCE) and also the ratio between polychromatic erythrocytes (PCE) to normochromic erythrocytes (NCE) was obtained.

Results: It was analyzed by one-way ANOVA followed by Dunnet's multiple comparison tests. Significant $(\mathrm{P}<0.01)$ increase in comet tail length and percentage of micronucleated polychromatic erythrocytes (\% MnPCE) was observed in groups treated with single and multiple doses of Cyclophosphamide whereas ornidazole and secnidazole treated groups did not show any significant changes.

Conclusions: The results indicate that Ornidazole and secnidazole are devoid of genotoxicity.
\end{abstract}

Keywords: Ornidazole, Secnidazole, Cyclophosphamide, Comet assay, Micronucleus assay, Genotoxicity

\section{INTRODUCTION}

Genetic toxicology is defined as the study of adverse effects on the process of heredity. ${ }^{5}$ As a discipline of toxicological research; it has been given the task of detecting mutagenic chemicals using an array of tests. Genotoxic profile of a drug can be established by in vitro and in vivo tests designed to detect genetic damage directly or indirectly by various mechanisms. Preclinical toxicity testing of a new molecule is an essential step in the drug discovery and development. In addition to general toxicity testing, now it is mandatory for a new molecule to be screened for its potential genotoxicity from regulatory point of view. ${ }^{1}$

The biology of genetic toxicity has intrinsic appeal for physicians and scientists associated with drug development. It gives vital clues about the inherent capacity of drugs to cause DNA damage and also defines the threshold dose capable of causing DNA damage. Various DNA damage biomarkers like micronucleus test, chromosomal aberration test, single cell gel electrophoresis test, unscheduled DNA synthesis assay, 
point mutation assay, tunnel assay etc., have been summarized by Fenech. ${ }^{4}$

Nitroimidazoles like ornidazole and secnidazole are the commonly used antimicrobials widely used in clinical practice. Ornidazole is a prototype nitroimidazole with broad spectrum activity against protozoa and many anaerobic bacteria. Information regarding metronidazole is well documented. Of late the gene interaction studies are gaining more importance. Ornidazole is known to act through its reductive activation of the nitro groups by susceptible microorganisms. ${ }^{9}$ It exerts cytotoxicity by damaging DNA and other critical biomolecules through reduction of nitro group which is electrophilic, ${ }^{10}$ and thereby found to inhibit cell mediated immunity to induce mutagenesis. This can predict its carcinogenicity and possibly its genotoxicity. In high doses metronidazole is reported to be carcinogenic in rodents ${ }^{6}$ and mutagenic in bacteria. ${ }^{15}$ It has been reported not only metronidazole and also its hydroxy metabolite is potentially genotoxic and carcinogenic. ${ }^{13}$ Presence of nitro group is has been suggested to be responsible for its mutagenic and genotoxic activity. ${ }^{9}$ On the other hand metronidazole has been reported to be non-genotoxicity in mice in some reports. ${ }^{19}$

Similarly, tinidazole has been suggested to posse's genotoxic and cytotoxic potential. ${ }^{8}$ However, there appears to be controversy regarding its genotoxicity. Reports regarding genotoxicity of ornidazole are very scanty few reports mentioning it as nongenotoxic ${ }^{19}$ there is paucity of information regarding genotoxicity of secnidazole and ornidazole. Therefore, the present study is planned to confirm the genotoxicity potential of metronidazole and tinidazole, and to explore the genotoxic effects of ornidazole and secnidazole in their maximal therapeutic equivalent doses in albino mice using micronuclei assay and single cell gel electrophoresis (comet assay).

In view of controversial reports the above mentioned nitroimidazole antimicrobial agents were explored for their genotoxic potential in albino mice using single cell gel electrophoresis (comet assay) and micronucleus assay.

\section{METHODS}

\section{Drugs \& Chemicals}

Ornidazole and Secnidazole were obtained as gift samples from Centaur Pharmaceuticals Ltd, Promed lab. Ltd. \& Wockhardt Pharm. Ltd. respectively. Cyclophosphamide (Endoxan @) was purchased from local market. Low melting Agarose (LMA), Normal Melting Agarose (NMA) and fetal bovine serum were obtained from HIMEDIA. Histopaque was obtained from Sigma (St. Louis, MO, USA). All other chemical reagents used were of analytical grade.
The clinically used maximum doses of these drugs were computed to mice equivalents with the help of the table devised by Paget and Barnes and were found to be $39 \mathrm{mg} / \mathrm{kg}$ for ornidazole, $52 \mathrm{mg} / \mathrm{kg}$ for secnidazole and $40 \mathrm{mg} / \mathrm{kg}$ for cyclophosphamide. All the drugs were administered orally except cyclophosphamide which was administered (i.p.) in the volume of $10 \mathrm{ml} / \mathrm{kg}$.

\section{Experimental Animals}

Swiss albino mice of either sex, weighing 20-25gm procured from central animal house of the institute were used in the present experiments. Animals were maintained on standard rodent feed (Amrut feeds) with drinking water ad libitum and maintained on a 12-hour light/dark cycle (8.00AM to 8.00PM). In addition, mice were acclimatized for 1 week to laboratory environment. They were housed, handled and sacrificed at the end of experiment in accordance with the guidelines of CPCSEA and the study was approved by Institutional animal ethical committee. The animals were divided in groups ( $n=5$ in each) to receive one of the treatments, both in acute as well as sub-acute studies. Control animals received equal volume of normal saline.

\section{Study design}

In acute study, blood and bone marrow samples were collected $24 \mathrm{hr}$ after the single dose treatment, whereas in sub-acute study doses were repeated for every $24 \mathrm{hr}$ for 7 times and the samples was collected $24 \mathrm{hrs}$ after the last dose.

\section{In vivo micronucleus assay}

24hrs after the last dose of drug treatment the animals were sacrificed by overdose of ether anesthesia and the bone marrow was collected for micronucleus assay as described by Schimd W. ${ }^{2}$ Both the femora were removed in toto, by cutting through pelvis and tibia and the bones were then freed from muscle fibres by the use of gauze and fingers. By gentle traction, the distal epiphysis was torn off, together with the rest of the tibia and the surrounding muscle. The proximal end of femur was carefully shortened with scissors until a small opening to the marrow canal becomes visible. The bone marrow was aspirated with the syringe (needle) of appropriate size by inserting it for few $\mathrm{mm}$ into the proximal part of the marrow canal. Then the femur was submerged completely in fetal bovine serum $(5 \mathrm{ml})$ contained in a centrifuge tube and subsequently, the marrow was aspirated by several gentle aspirations and flushing. This process was also repeated from the distal end of the femur and the tube was shaked, so that bone marrow cells get into the serum as a fine suspension and not settle down in the form of gross particles. Then the tube was centrifuged at 1000 revolution per minute for 5 minutes to isolate the bone marrow cell as a pellet. This pellet was suspended in 1-2 drops of foetal bovine serum, and drops of this suspension were put on glass slides so as to prepare bone marrow smears. These slides were air dried 
and stained with undiluted May Gruenwald (MG) stain for $3 \mathrm{~min}$ followed by diluted $\mathrm{MG}$ stain (1:1; with distilled water) for 2 minutes. Later, slides were stained with diluted geimsa stain (1:6; with distilled water) for 10 min. The slides were then rinsed in distilled water and backside was cleared by methanol and then they were air dried and mounted permanently with cover slips. These slides were observed under microscope (oil immersion) for the presence of micronuclei in 2000 polychromatic erythrocytes (MnPCE) per animal. Bone marrow toxicity was assessed by the incidence of polychromatic erythrocytes (PCE) per 200 total erythrocytes.

\section{Comet assay (Single Cell Gel Electrophoresis - SCGE)}

$24 \mathrm{hrs}$ after the last dose drug treatment, about $0.5 \mathrm{ml}$ of blood was collected from retro orbital sinus, and was mixed with double amount of phosphate buffer solution (PBS) and was processed for SCGE (comet assay) as described earlier by Rojas E. et al 1999. ${ }^{3}$ The blood sample was then gently layered over the histopaque in a centrifugation tube which was centrifuged at 1000 revolution per minute for 25-30minute to obtain a white band containing lymphocytes. This band is now aspirated out into a micro-centrifuge tube with the help of pasture pipette and is mixed with $0.5 \%$ LMA (to form as second layer on the slides). Frosted glass slides are taken to form a 3 layered agar bed- bottom (first) layer is composed of $0.67 \%$ NMA; middle (second) layer consists of $0.5 \%$ LMA in which lymphocytes were suspended earlier. Finally the middle layer was covered by $0.5 \%$ LMA to form top (third) layer. These slides were then kept in lysis buffer $(2.5 \mathrm{M} \mathrm{NaCl}, 100 \mathrm{mM}$ EDTA, $10 \mathrm{mM}$ Tris $\mathrm{HCl}$, $10 \%$ DMSO, $1 \%$ Triton $\mathrm{X} 100, \mathrm{pH}=10$ ) for $2-3 \mathrm{hr} /$ overnight. After that slides were incubated for $20 \mathrm{~min}$ in electrophoresis buffer (100mM EDTA, 300mM NaOH, $\mathrm{pH}>13$ ) prior to electrophoresis at $25 \mathrm{~V}$ and $300 \mathrm{~mA}$ carried out for $1 \mathrm{hr}$. After electrophoresis, slides were washed 2-3 times with neutralization buffer (0.4M Tris $\mathrm{HCl} \mathrm{pH>7.5)} \mathrm{and} \mathrm{were} \mathrm{air} \mathrm{dried.} \mathrm{These} \mathrm{slides} \mathrm{were} \mathrm{then}$ immersed in absolute ethanol for $3 \mathrm{~min}$ to precipitate the DNA.]. Air dried slides were then immersed in fixing solution $(75 \mathrm{gm}$ trichloroacetic acid, $25 \mathrm{gm}$ zinc sulphate, $25 \mathrm{gm}$ glycerol in $500 \mathrm{ml}$ distilled water) for 10 minutes and then were washed with double distilled water for 6-8 times before they were air dried for about 1 hour. Subsequently, silver staining was carried out by the procedure of Nadin et al, ${ }^{18}$ where $68 \mathrm{ml}$ of staining solution B (100mg ammonium nitrate, 100mg silver nitrate, $500 \mathrm{mg}$ tungstosilic acid, $250 \mu \mathrm{l}$ of formaldehyde in $500 \mathrm{ml}$ double distilled water) was mixed with $32 \mathrm{ml}$ of staining solution A (25 gm sodium carbonate in $500 \mathrm{ml}$ double distilled water) and poured into a couplin jar. The slides were dipped vertically in these staining filled couplin jars until grayish color developed on the slides. Staining was stopped by dipping the slides in stopping solution (1\% glacial acetic acid) for 5 minutes. Whole procedure was carried out in dim light to minimize artificial DNA damage.

All the slides were coded before evaluation and then were observed under microscope (45X). 100 comets were scored per animal, (50 in each of two replicate slides). By trypan blue exclusion method, samples with less than $90 \%$ viable lymphocytes were rejected. Comet head diameter and total comet length were measured using ocular micrometer which was calibrated with the help of stage micrometer and tail length was calculated by formula:

Comet tail length $(\mu \mathrm{m})=$ Total comet length - Head diameter

\section{Statistical analysis}

All the results were expressed as Mean \pm S.E.M. To compare different groups with saline group, one-way analysis of variance (ANOVA) was done, followed by Dunnet's post hoc test. $\mathrm{P}<0.05$ was considered to be significant.

\section{RESULTS}

In in vivo micronucleus assay, the incidence \% MnPCE per 2000 polychromatic erythrocytes (PCE) was calculated in all the drug treated groups both in acute as well as sub-acute studies. In acute study mean \% MnPCE was, $0.515 \pm 0.007,0.160 \pm 0.012,0.165 \pm 0.010,0.165 \pm$ $0.010,0.100 \pm 0.105$ for metronidazole, tinidazole, ornidazole and secnidazole respectively in Normal saline, treated groups respectively. However, in cyclophosphamide treated group the mean \% MnPCE was significantly $(\mathrm{P}<0.01)$ increased with $3.53 \pm .039$ in contrast to other drug treated groups. Similar results were also obtained in the sub-acute study groups (Table 1 and Table 2).

Table 1: Incidence of \% MnPCE (in 2000PCE) in acute \& sub-acute studies.

\begin{tabular}{|llllll|}
\hline Sr. No. & $\begin{array}{l}\text { Treatment group }(\mathrm{mg} / \mathrm{kg}) \\
(\mathbf{n}=\mathbf{5})\end{array}$ & $\begin{array}{l}\text { Acute study } \\
\text { \% MnPCE } \\
\text { Mean } \pm \text { S.E.M }\end{array}$ & $\begin{array}{l}\text { \%PCE } \\
\text { Mean } \pm \text { S.E.M }\end{array}$ & $\begin{array}{l}\text { \%ub-acute study } \\
\text { Mean } \pm \text { S.E.M }\end{array}$ & $\begin{array}{l}\text { \%PCE } \\
\text { Mean } \pm \text { S.E.M }\end{array}$ \\
\hline 1. & Control (saline) $8 \mathrm{ml} / \mathrm{kg}$ & $0.100 \pm 0.105$ & $58.60 \pm 1.364$ & $0.110 \pm 0.012$ & $55.50 \pm 1.000$ \\
\hline 2. & CP $40 \mathrm{mg} / \mathrm{kg}$ & $3.53 \pm .039$ & $56.20 \pm 1.158$ & $3.555 \pm 0.383$ & $53.40 \pm 1.269$ \\
\hline 5. & ORZ $39 \mathrm{mg} / \mathrm{kg}$ & $0.165 \pm 0.010$ & $57.24 \pm 1.164$ & $0.175 \pm 0.008$ & $55.76 \pm 1.152$ \\
\hline 6. & SDZ $52 \mathrm{mg} / \mathrm{kg}$ & $0.165 \pm 0.010$ & $56.45 \pm 1.245$ & $0.170 \pm 0.008$ & $54.34 \pm 1.236$ \\
\hline
\end{tabular}

One-way ANOVA, $\mathrm{F}_{5,24}=536.1$ (acute study); 201.1 (sub-acute study); $\mathrm{P}<0.0001 \quad * \mathrm{P}<0.0001$ (Student' $\mathrm{t}^{\prime}$ test) 
Table 2: Dunnett's multiple comparison test.

\begin{tabular}{|llll|}
\hline $\begin{array}{l}\text { Sr. } \\
\text { No. }\end{array}$ & $\begin{array}{l}\text { Group } \\
\text { comparisons }\end{array}$ & $\begin{array}{l}\text { P value for } \\
\text { acute study }\end{array}$ & $\begin{array}{l}\text { P value for } \\
\text { sub-acute study }\end{array}$ \\
\hline 1. & Control vs. CP & $\mathrm{P}<0.01$ & $\mathrm{P}<0.01$ \\
\hline 2. & Control vs. ORZ & $\mathrm{P}>0.05$ & $\mathrm{P}>0.05$ \\
\hline 3. & Control vs. SDZ & $\mathrm{P}>0.05$ & $\mathrm{P}>0.05$ \\
\hline
\end{tabular}

In comet assay, mean comet tail length was calculated in all the drug treated groups both in acute as well as sub- acute studies. In acute study, the saline treated (negative control) group showed a mean value of $3.056 \pm 0.184$ which did not differ significantly from that of the groups treated with tinidazole, ornidazole and secnidazole. As expected, cyclophosphamide treated group showed a significant $(\mathrm{P}<0.01)$ increase in comet tail length with the mean of $23.030 \pm 0.446$ in contrast to other drug treated groups. Similar results were also observed in sub-acute study groups (Table 3 and Table 4).

Table 3: Comet tail length $(\mu \mathrm{m})$ in acute $\&$ sub-acute study.

\begin{tabular}{|llllll|}
\hline Sr. No. & Group $[\mathbf{n}=5]$ & Treatment & Tail length $(\boldsymbol{\mu m})$ & Cell viability (\%) \\
\cline { 1 - 4 } & & & Acute & Sub-acute & \\
\hline 1. & Negative control & Normal saline & $3.056 \pm 0.184$ & $3.247 \pm 0.104$ & $>96$ \\
\hline 2. & Positive control & Cyclophosphamide & $23.030 \pm 0.446$ & $28.24 \pm 0.436$ & $>95$ \\
\hline 4. & Group 3 & Ornidazole(ORZ) & $3.473 \pm 0.114$ & $0.362 \pm 0.242$ & $>95$ \\
\hline
\end{tabular}

One-way ANOVA, $\mathrm{F}_{5,24}=481.7$ (acute study); 458.8(Sub-acute study); $\mathrm{P}<0.0001 \quad * \mathrm{P}<0.0001$

Table 4: Dunnett's multiple comparison test.

\begin{tabular}{|c|c|c|c|}
\hline $\begin{array}{l}\text { Sr. } \\
\text { No. }\end{array}$ & $\begin{array}{l}\text { Group } \\
\text { comparisons }\end{array}$ & $\begin{array}{l}P \text { value for } \\
\text { acute study }\end{array}$ & $\begin{array}{l}\text { P value for } \\
\text { sub-acute study }\end{array}$ \\
\hline 1. & Control vs. CP & $\mathrm{P}<0.01$ & $\mathrm{P}<0.01$ \\
\hline 2. & Control vs. ORZ & $\mathrm{P}>0.05$ & $\mathrm{P}>0.05$ \\
\hline 3. & Control vs. SDZ & $\mathrm{P}>0.05$ & $\mathrm{P}>0.05$ \\
\hline
\end{tabular}

Comparing acute and sub-acute study groups, it was found that there was a significant increase in comet tail length \& \% MnPCE in only cyclophosphamide treated group $(\mathrm{P}<0.01)$ among all the treatment groups.

\section{DISCUSSION}

In summary, ornidazole and secnidazole do not have genotoxic potential in mice as observed in the present study. Ornidazole is known to act through its reductive activation of the nitro groups ${ }^{10}$ by susceptible microorganisms in high doses metronidazole has been reported to be carcinogenic in rodents and mutagenic in bacteria. ${ }^{15,16}$ Presence of nitro group is has been suggested to be responsible for its mutagenic and genotoxic activity. ${ }^{7,10}$ On the other hand metronidazole has been reported to be non-genotoxicity in mice $^{6}$ and human ${ }^{17}$ studies. Ornidazole is a prototype nitroimidazole. Similarly, tinidazole has been suggested to posses' genotoxic and cytotoxic potential. ${ }^{8}$ However there appears to be controversy regarding its genotoxicity. ${ }^{17}$ There is paucity of information regarding genotoxicity of secnidazole. Therefore, the present study was planned to explore the genotoxicity potential of nitroimidazoles like metronidazole, secnidazole, secnidazole and ornidazole in their therapeutic equivalent doses in albino mice.

Mechanisms like oxidative DNA damage caused by metronidazole in hepatocytes and antioxidants have been shown to protect the hepatocytes against such damage. ${ }^{14}$ It is well known that DNA damage and apoptosis are physiological phenomenon and damaged DNA either gets repaired or leads to apoptosis. Logically, when damage exceeds the capabilities of repair process or when normal repair mechanisms fail, genotoxicity manifests in the form of either formation of MnPCE or comets. It has been suggested that physiological levels of steroids are necessary for induction of micronuclei by metronidazole, since pretreatment with mifepristone (RU 486) or adrenalectomy prevented formation of micronuclei by metronidazole. Dexamethasone ${ }^{12}$ and estrogen ${ }^{11}$ have been reported to produce micronuclei formation in in vitro studies even in absence of morphine. These reports lead to debate whether steroids potentiate genotoxicity of metronidazole or vice versa. It appears that an elevated corticosterone level is not mandatory for induction of micronuclei formation indicating permissive role of corticosterone to accomplish metronidazole genotoxicity.

In the present study clinical equivalent doses of nitroimidazoles were used. In clinical practice, ornidazole and secnidazole are widely used in protozoal infections. The findings of the present study if extrapolated to humans clearly indicate that metronidazole could be genotoxic in clinical doses. However, such a toxicity of the concerned nitroimidazoles needs to be confirmed clinically.

\section{Funding: No funding sources \\ Conflict of interest: None declared \\ Ethical approval: The study was approved by the institutional animal ethics committee}

\section{REFERENCES}

1. Jena GB, Kaul CL, Rama RP. Genotoxicity testing, a regulatory requirement for drug discovery and 
development: Impact of ICH guidelines. Indian Journal of Pharmacology. 2002;34:86-9.

2. Schmid W. The micronucleus test. Mutation research. 1975;31:9-15.

3. E. Rojas, M.C. Lopez, M. Valverde, Single cell gel electrophoresis assay: methodology and applications, Journal of Chromatography. 1999;B722:225-54.

4. Fenech M. Biomarkers of genetic damage for cancer epidemiology. Toxicology. 2002;181-182:411-6.

5. G. Krishna, Hayashi M. In vivo rodent micronucleus assay: Protocol, conduct and data interpretation. Mutation research. 2000;455:155-66.

6. Dobias L, Cerna M, Rossner P, Sram R. Genotoxicity and carcinogenicity of metronidazole. Mutat Res. 1994Jun;317(3):177-94.

7. Bendesky A, Menendez D, Ostrosky-Wegman P. Is metronidazole carcinogenic? Mutat Res. 2002 Jun;511(2):133-44.

8. Voogd CE, Van der Stel JJ, Jacobs JJ. The mutagenic action of nitroimidazoles. II. Tinidazole, ipronidazole, panidazole and ornidazole. Mutat Res. 1977 Apr;48(2):155-61.

9. Rang HP, Dale MM, Ritter JM, Moore PK. Pharmacology. $5^{\text {th }}$ ed. Edinburg: Churchill Livingstone; 2003.

10. Hardman JG, Limbard LE. Goodman \& Gilman's The Pharmacological Basis of Therapeutics. $10^{\text {th }} \mathrm{Ed}$. New York: McGraw-Hill Medical publishing division; 2001.

11. Hundal BS, Dhillon VS, Sidhu IS. Genotoxic potential of estrogens. Mutation Research. 1997;389:173-81.

12. Sawant SG, Kozlowski RS, Couch DB. The role of adrenal corticosteroids in induction of micronuclei. Mutation Research. 2001;498:129-33.
13. Menendez D, Bendesky A, Rojas E, Salamanca F, Ostrosky-Wegman P. Role of P53 functionality in the genotoxicity of metronidazole and its hydroxy metabolite. Mutat Res. 2002Apr25;501(1-2):57-67.

14. Hrelia P, Murelli L, Paolini M, Cantelli-Forti G. In vivo protective role of antioxidants against genotoxicity of metronidazole and azanidazole. Drugs Exp Clin Res. 1987;13(9):577-83.

15. Cantelli-Forti G, Aicardi G, Guerra MC, Barbaro AM, Biagi GL. Mutagenicity of a series of 25 nitroimidazoles and two nitrothiazoles in Salmonella typhimurium. Teratog Carcinog Mutagen. 1983;3(1):51-63

16. Gómez-Arroyo S, Melchor-Castro S, VillalobosPietrini R, Camargo EM, Salgado-Zamora H, Campos Aldrete ME. Cytogenetic study of metronidazole and three metronidazole analogues in cultured human lymphocytes with and without metabolic activation. Mutat Res. 2004Jun;18(3):31924.

17. Carballo MA, Palermo AM, Mudry MD. Toxicogenetic evaluation of metronidazole in the treatment of women infected with Trichomonas vaginalis Mutat Res. 2004Mar;98(2):139-47.

18. S.B. Nadin, L.M. Vargas-Roig, D.R. Ciocca, A silver staining method for single-cell Gel assay, The journal of histochemistry and cytochemistry. 2001;49:1183-6.

19. Fahrig R, Engelke M. Reinvestigation of in vivo genotoxicity studies in man. I. No induction of DNA strand breaks in peripheral lymphocytes after metronidazole therapy. Mutat Res. 1997 Dec12;395(2-3):215-21.

doi:10.5455/2319-2003.ijbcp20140217

Cite this article as: Revankar SP, Vedavathi $\mathrm{H}$

Genotoxic evaluation of ornidazole and secnidazole in albino mice: an experimental study. Int J Basic Clin Pharmacol 2014;3:139-43. 